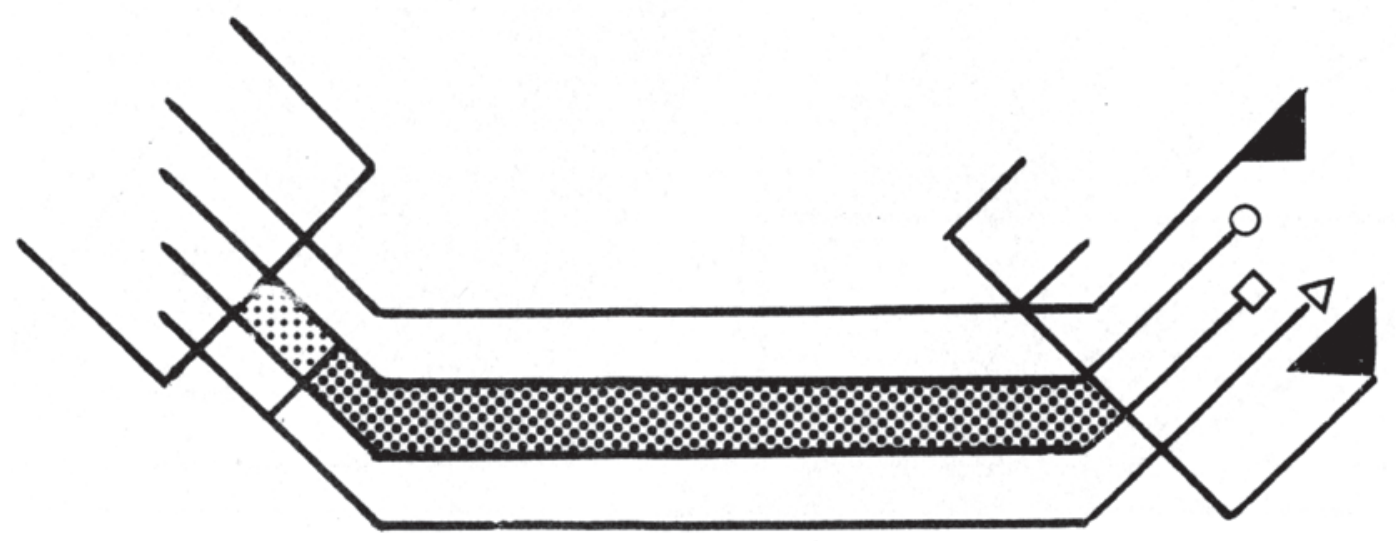


n. 26 Entre a abstração e a imagem realista: pintura no limite

palavras-chave:

pintura; pintura abstrata $x$ figurativa; arte contemporânea; arte moderna, Gerhard Richter

keywords: painting; abstract $x$ figurative painting; contemporary art; modern art; Gerhard Richter

\section{Between Abstraction and Realism: Painting on the edge}

Este texto pretende fazer uma reflexão sobre a pintura contemporânea, que se destaca por ficar no limite entre dois conceitos clássicos da arte moderna: "figurativo" e "abstrato". O artigo baseia-se em autores da teoria da arte moderna (como Clement Greenberg e Leo Steinberg) da filosofia (como Jacques Rancière), da teoria da arte contemporânea (como Anne Cauquelin) e nos escritos do pintor alemão Gerhard Richter.

This text aims to reflect on contemporary painting that stands out for being on the borderline between two classic concepts of modern art: "figurative" and "abstract." The paper is based on authors from the theory of modern art (such as Clement Greenberg and Leo Steinberg), from philosophy (such as Jacques Rancière), from the theory of contemporary art (such as Anne Cauquelin) and from writings by the German painter Gerhard Richter.

\footnotetext{
* doutora em Poéticas Visuais pela Escola de Comunicações e Artes da Universidade de São Paulo (ECA USP).
} 
132

Do Modernismo e do Conceitualismo, o pintor contemporâneo guarda a crença de que deve considerar seu trabalho não apenas como uma pintura, mas como a representação de uma ideia sobre ela, não importando mais se vai optar pela abstração ou pela representação, se vai transitar pelas duas ou ficar no meio delas.

Pode-se dizer que, hoje, a pintura existe não para representar a imagem, mas que a imagem existe para representar a ideia de pintura.

O par figuração e abstração, cujo dualismo está na gênese da arte moderna e que foi tema de debate até a época do Expressionismo Abstrato americano, estabeleceu uma dicotomia que, ao longo do tempo, criou rótulos.

Abstrato e figurativo tornaram-se, além de elementos de identificação, conceitos decisivos em um trabalho de pintura.

Hoje, na primeira década do século XXI, essa contradição não faz mais sentido. Desde Gerhard Richter, não se questiona mais se um pintor pode ser "realista fotográfico" e "abstrato gestual" ao mesmo tempo; o que importa é: como ele apresenta seu trabalho e como ele defende sua posição sobre o meio que escolheu.

É estranho falar de um conteúdo específico quando, de um lado, tudo é possível, e de outro, todo artista é solicitado a inventar uma postura que o diferencie de outros colegas. Mas, paradoxalmente, em tal situação, a própria "autoinvenção" transforma-se no tema básico que une tudo o que é contrário, até mesmo projetos contraditórios. Percebe-se aí o pluralismo na arte que, segundo Arthur Danto, "implica antes uma transformação fundamental da autoconsciência artística; quase uma revolução no modo como os artistas estão agora começando a pensar sobre o futuro da arte" ${ }^{\text {. }}$

Diferentemente dos primeiros artistas modernistas - que, ao escrever sobre arte, visavam "ensinar" uma nova maneira de ver, única e correta - , o artista de hoje, quando escreve ou se posiciona frente às questões inerentes ao seu trabalho, quer mostrar as múltiplas possibilidades do fazer e ao mesmo tempo suas dúvidas e tropeços. Encontrar maneiras de realizar um trabalho, mais do que resolver um problema, tornou-se o próprio "problema” da arte. Nenhum método particular, "olhar" consistente, tipo de material, tema ou motivo identifica a pintura como contemporânea ou a desqualifica como tal.

Pode-se dizer que até os anos 1980 ainda havia alguma coisa que identificava uma tendência. A pintura que se denominou

\section{Fátima Junqueira}

Entre a abstração e a imagem realista: pintura no limite
1. DANTO, Arthur C. Aprendendo a viver com o pluralismo. In: Revista Valise, v.1, n. 2, ano 1. Porto Alegre, dez. 2011, p. 148. 

sistemática, um espaço não naturalista, menos geométrico e pouco minimal — isso não quer dizer que, paralelamente, artistas estabelecidos não continuassem fazendo suas pinturas como sempre fizeram, mas muitos também adotaram algumas das características dessas tendências para fazer com que seus trabalhos fossem mais exibidos.

Hoje, comparada a outras formas de expressão artística, a pintura é menos politicamente carregada do que pareceu ser um dia. Ao mesmo tempo, ao assumir seu caráter gratuito, tomando consciência de sua inocuidade, a pintura transforma-se numa arte que "evolui sem saber que é arte, uma arte que tem a chance de começar do zero", como afirmou uma vez, Claes Oldenburg ${ }^{2}$. Mas, na verdade, ele manifesta-se contra a pintura e toda arte de museu e a favor do happening e do environment - termo que antecede instalação —, que não dependiam de instituições museológicas. Curioso notar que justamente o tipo de arte que ele defendia e que queria que representasse um contraponto para a pintura é a que virou o grande evento do museu hoje.

Uma frase do pintor alemão Gerhard Richter explicaria melhor a atitude do pintor contemporâneo: "Gostaria de que tudo fosse muito evidente, simples e preciso, e não gostaria de fazer nenhuma arte a não ser uma pintura qualquer, indeterminada” ${ }^{3}$.

Ao se tirar o holofote da pintura, permitiu-se que a mesma se tornasse um personagem com mais chances de obter novos papéis, o que não deixa de ser uma aspiração ao novo, mas um novo que não rompe e nem continua com tradições e não precisa mais provar que é novo.

Embora muitas pinturas atuais representem coisas ou pessoas reconhecíveis, poucos artistas estão engajados com a representação no sentido clássico do termo, ou seja, a maneira que dominou a pintura ocidental da Renascença, passando pelo Impressionismo e ainda tendo alguma relevância no fim do século XX.

Por ter predominado por tanto tempo, ainda hoje persiste a ideia de que a "imagem realista" é algo natural, que funciona como apresentação e não representação da realidade e por esse motivo a pintura do

2. Apud FERREIRA, Glória \& COTRIM, Cecilia (org.). Escritos de artistas: anos 60/70. Rio de Janeiro: Jorge Zahar Ed., 2006, p. 67

3. Idem, p. 116. passado buscou a natureza como modelo e sempre foi considerada a imagem mais fiel da realidade, a mais "verdadeira". Mas isso para os olhos do espectador comum! Em uma referência a Clement Greenberg e ao tratamento que este deu para a arte pré-moderna e à consequente oposição do modernismo aos grandes mestres, Leo Steinberg levanta que: 
134

[...] o problema, ao que parece, está ligado ao ilusionismo da pintura dos grandes mestres - a suposta intenção que tinha sua arte de enganar e simular. Ora, não pode haver dúvida de que há, e de que sempre houve, pessoas que olham imagens realistas como se fossem reais - mas que tipo de pessoas? ${ }^{4}$

Para Steinberg, os grandes mestres do passado sempre levaram em conta a tensão entre a superfície e a ilusão porque estavam preocupados em ocultar a arte fazendo arte, não se interessavam em explicar essa tensão. "A diferença 'objetiva' entre grandes mestres e modernistas se reduz às tendências subjetivas do espectador" .

Quando olhamos para uma pintura antiga, automaticamente a associamos à ilusão da realidade, antes de vê-la como pintura. Muitas vezes associamos esboços dos grandes mestres à arte moderna, quando esse esboço é parte essencial para a realização da obra que esconde o processo.

Steinberg conclui que o método de trabalho de Mark Rothko, por exemplo, funda-se no ilusionismo e que sua pintura é muito aérea, como massas de cor flutuando no espaço ${ }^{6}$.

Gerhard Richter ${ }^{7}$, referindo-se aos borrões que faz em suas pinturas, explica que o fato de borrar não é o mais importante e nem uma marca que identifica seus quadros, pois quando dissolve as delimitações, cria transições em fluxo, superfícies lisas, equalizadoras, que tornam a "apresentação confiável". Se assim não fosse, ou seja, se fosse pastosa, por exemplo, recordaria demais a pintura e destruiria a ilusão.

A ótica da visão objetiva, instaurada pelos aparatos óticos desde os primórdios da Renascença e depois solidificada com a descoberta da fotografia no século XIX, fez com que a pintura reforçasse e afirmasse sua bidimensionalidade. Isso implicou em uma estruturação e abstração da realidade.

Antes disso, a qualidade da pintura era medida de acordo com sua maior ou menor proximidade com esquemas óticos da realidade. O estilo era considerado mais uma deformação da percepção que uma vantagem. $\mathrm{O}$ olho do pintor devia ser um intermediário neutro.

Quando Richter ${ }^{8}$ nega o estilo, quer evitar a deformação no sentido moderno do termo. Para ele, o efeito da pintura é maior quando é "diferente", quando sai do "normal". Pintura "normal" para a maioria das pessoas é a que tem a "marca do artista". Nesse sentido, Richter nega o Modernismo, mas também não volta para a tendência naturalista da pintura do passado porque seu modelo não é a natureza, mas a

\section{Fátima Junqueira}

Entre a abstração e a imagem realista: pintura no limite

\author{
4. Apud FERREIRA, Glória \\ \& COTRIM, Cecilia. Clement \\ Greenberg e o debate crítico. \\ Rio de Janeiro: Funarte Jorge \\ Zahar, 1997, p. 188. \\ 5. Idem, p.189. \\ 6. Idem, p.190. \\ 7. Cf. Apud FERREIRA \& \\ COTRIM. Op. cit., 2006, p. 117.
}



"esconder a arte com a arte".

Segundo Laura Gonzales Torres, a arte moderna é o momento em que os conceitos relativos à objetividade do real, mimese e beleza são questionados e a função da pintura sofre uma mudança. Assim, a tarefa da pintura moderna será destruir as convenções relativas a valores inerentes da visão objetiva, da visão naturalista da arte. Esses valores são: a objetividade da mimese, a beleza como regra e a habilidade manual como recurso. Para se afastar do representacional no sentido de mimese, a pintura vai buscar um outro tipo de norma que será definida na própria disciplina da pintura. Seu tema deve vir do consenso com a forma e sua qualidade será o conceito surgido no processo do pintor dentro das convenções da pintura. Greenberg 9 afirma que a "qualidade" da pintura moderna está no seu conteúdo e vice-versa.

$\mathrm{O}$ que a pintura contemporânea contrapõe à moderna é principalmente em relação à imposição de uma maneira única e necessária de olhar para uma pintura, seja ela dos grandes mestres do passado, seja dos modernistas.

Por algum tempo, a arte tomou a austeridade de certos conceitualistas e com ela, em nome da política, fez acreditar que o prazer não cabia, que a estética era suspeita e que somente alguma coisa antiestética ou desagradável justificaria uma pintura, uma pintura acima de tudo intelectual e fria.

Para os pintores contemporâneos, estar na borda que separa a representação objetiva da realidade da abstração é mais estimulante que fazer uma pintura abstrata ou figurativa. Por isso, escolhem transitar entre os dois lados e fazem uma pintura que celebra a oscilação e a ambiguidade. O que interessa é a qualidade de amorfia que uma imagem pode ter e, diferente da deformação moderna que se caracteriza como estilo ou marca do artista, a desfiguração na pintura contemporânea busca representar um estado de metamorfose.

Mas não se pode dizer que esse tipo de busca não esteja presente nos modernos. Pode-se comprová-lo através de um texto de Mario Pe-

8. Idem, p. 113.

9. Apud GONZALES FLORES, Laura. Fotografia e pintura: dois meios diferentes? São Paulo: Ed.WMF Martins Fontes, 2001, p. 40. drosa sobre Ismael Nery:

Em tudo procurava ele a forma ou a definição, e, necessariamente, a antiforma e a antidefinição, que ia discernir na matéria ainda não a chegada à forma, ou na forma em marcha para o dilaceramento ou a dissolução. Ele abordava 
136

as coisas primeiramente por sua definição formal linear, mas logo a seguir uma curiosidade inexorável pelas entranhas das coisas o obrigava a prosseguir e a rasgar os invólucros externos, em busca de novas especulações ${ }^{10}$.

Um outro dado muito presente nesse tipo de pintura é a afirmação de sua picturalidade. Segundo Greenberg ${ }^{11}$ o conceito de pictórico, que vem do malerisch de Wölfflin, designa as qualidades formais da arte barroca e significa, entre outras coisas, a definição de ambiguidade, de fragmentação, imprecisão de cor e de contorno, ou seja, o oposto da linearidade. Mas a linha que divide os dois conceitos, linear e pictórico, não é rigorosa nem inflexível. Ele lembrou também que, tanto na arte moderna quanto na arte anterior, podiam-se constatar esses elementos e que muitos artistas combinavam ambos.

O Expressionismo Abstrato, por exemplo, é ao mesmo tempo abstrato e pictórico - o que vinte anos antes era uma combinação bastante inesperada, lembrando-se que a abstração das décadas de 1920 e 1930 se identificava com as silhuetas planas e contornos precisos do Cubismo Sintético ${ }^{12}$.

A pintura contemporânea se livrou da incumbência de ser pintura. A arte em geral não tem mais o compromisso de questionar se alguma coisa é arte.

Anne Cauquelin, ao se referir ao abandono de posições fixas na arte, ou ao despojamento afirma:

O movimento de despojamento investe primeiramente contra o mercado digamos contra o sistema tradicional de exposição -, depois, do mercado, desloca-se para a obra e, da obra, para o próprio gesto de despojamento; desse modo, a arte se vê como que esvaziada desde o interior, em busca de sua própria desmistificação ${ }^{13}$.

Concebe ainda que, quando alguém, ao se referir a uma obra diz: "isso não é arte”, pode-se considerar um elogio, pois

não é a arte no sentido que é dado a essa atividade, mas em outro, que não vemos porque ela é sem obra nem autor, ou pelo menos é o que se tenta fazer com todos os tipos de manipulações, mutações e invenções ${ }^{14}$.

Em grande parcela, a arte contemporânea se submete ao regime
Fátima Junqueira

Entre a abstração e a imagem realista: pintura no limite

10. PEDROSA, Mario. Acadêmicos e modernos: textos escolhidos III. São Paulo: Editora da Universidade de São Paulo, p. 198.

11. Apud FERREIRA \& COTRIM. Op. cit., 1997, p. 111.

12. Ibidem.

13. CAUQUELIN, Anne Frequentar os incorporais: contribuição a uma teoria da arte contemporânea. São Paulo: Martins, 2008, p. 87-88.

14. Idem, p. 88. 
ARS de operações mentais que abrigam metáforas. Isso quando encontram ano 13 correspondências no campo do visual, como por exemplo, a cor branca n. 26 correspondendo ao vazio e metáfora do invisível. É desse modo que Cauquelin estabelece uma relação entre os elementos incorporais dos estoicos e a arte contemporânea. O vazio é apenas um desses elementos e, diga-se, muito pertinente.

De algum modo, a velha pergunta herdada dos conceitualistas "Isto é arte?" como inerente ao próprio conceito de arte, perde a razão de ser, uma vez que não há mais a necessidade de algo "ser" arte. A pergunta seria então: "Isso precisa ser arte?" como o artista Cory Arcangel bem colocou, referindo-se a mudanças no campo da mídia nos últimos anos: "Não existe mais rua de mão única. Tudo é participativo. As pessoas simplesmente fazem coisas. E eu não sei se é necessário revelar alguma coisa mais" ${ }^{15}$.

O trabalho de arte deixou de querer nos libertar e, desse modo, liberta-nos ao deixar-nos livres para escolher nossa própria leitura ou realizar nossa tradução. Mas se a crítica está nos olhos do espectador, sua transcendência do convencional vem à custa da mudança de seus valores culturais. Por isso a pergunta "Isso precisa ser arte?" é pertinente. Por que suportar a palavra arte se ela não se refere mais a algo que tem um significado cultural e, portanto, compartilhado?

Retomando o assunto da pintura de que trata este texto, pode-se concluir que mais do que tratar de dois elementos da "pintura", o abstrato e o figurativo, o artista de hoje está preocupado em criar uma relação com seus espectadores e destacar o próprio potencial de transição que engloba essa dicotomia, deixando para o observador a decisão sobre o que e como ver.

Em outras palavras, mesmo parecendo ilusório e até utópico um resquício dos modernos - o que interessa a esses pintores é introduzir um tipo de igualdade, presumindo as mesmas capacidades para o artista e para o observador. Isso permite com que o espectador traduza a obra e organize-a de acordo com sua própria história e referências.

Lembrando Jacques Rancière ${ }^{16}$, em seu discurso "O espectador emancipado”, publicado na Artforum, em 2007:

Uma arte é emancipada e emancipadora quando renuncia à au-

17. Apud CARNEVALE, Fulvia \& KELSEY, John. Art of the possible: an interview with Jacques Rancière. In: Artforum, Março de 2007, p. 258. toridade da mensagem imposta, ao público-alvo e ao modo universal de explicar o mundo; quando, em outras palavras, deixa de querer nos emancipar ${ }^{17}$. 
Isso vem reforçar a ideia de que não existe uma forma nova e melhor de ver uma pintura, como tentavam provar os modernistas, e que nem mesmo chamar de pintura uma imagem pintada é necessário; assim como não o é, ainda menos, ser pura.

Greenberg quis mostrar que em alguns momentos a arte moderna se revela disciplinada demais, demasiado voltada para a tradição e para a convenção e que a planaridade da pintura modernista jamais deveria ser absoluta.

Notamos que, mesmo com seu alerta para o risco da arte moderna tornar-se muito tradicional e convencional, ele não negou que as normas essenciais eram condição necessária para a pintura ser reconhecida como arte.

Por outro lado, quando consideramos o pluralismo na arte e as teorias de emancipação de Rancière, eliminamos as normas estéticas, ou melhor, constatamos uma igualdade de regras estéticas. Assim, o "essencialismo" modernista perde o sentido.

Para concluir, lembremo-nos que Duchamp dizia: "arte é sempre uma escolha”. O que quer dizer: haverá sempre exclusões e um artista faz sempre opções, mesmo que seu trabalho pareça contraditório, ambíguo, que negue regras ou que transite por várias vertentes. A negação de uma regra é a criação de outra.

Caberia ainda acrescentar que nesse tipo de pintura, em que a abstração e a representação da realidade se misturam, tem-se a sensação de que uma espécie de paisagem da mente é criada. $\mathrm{O}$ pintor pode ser comparado com um turista que combina curiosidade e deslumbramento com incompreensão e desconfiança. Tal pintura incute a ideia de sentimentos conflitantes inerentes a esse tipo de perspectiva da realidade. Essa mistura pictórica de figuração e abstração reflete um mundo familiar e estranho ao mesmo tempo. Não é novidade, portanto, e nem quer ser; não faz relação com o inconsciente, nem faz apologia à forma ou ao plano; mas não deixa de ser um mapa formal da mente num plano bidimensional onde cores, gestos e matéria se encontram.

Fátima Junqueira (São Paulo, 1965) é artista plástica e doutora em Poéticas Visuais pela Escola de Comunicações e Artes da Universidade de São Paulo. Trabalha principalmente com pintura.

\section{Fátima Junqueira}

Entre a abstração e a imagem realista: pintura no limite
Artigo recebido em 14 de Agosto de 2015 e aprovado em 28 de Agosto de 2015.

Wlademir Dias-Pino 3 versões do Solida 1956. 


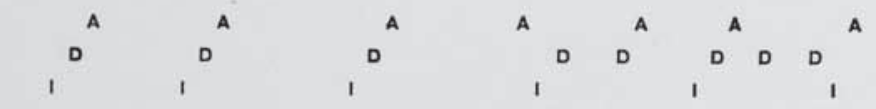

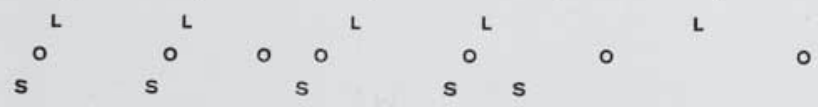

$$
\begin{aligned}
& \therefore A, 1, M^{\prime} / \mu^{v} \\
& \mathrm{~S}^{\mathrm{L}^{\mathrm{I}^{\mathrm{A}}}} \\
& \text { Wlademir Dios Pino: } 3 \text { versōes do Solida } 1956
\end{aligned}
$$

